\title{
Brief resolved unexpected event: prevalence, etiology and epidemiologic characteristics in Lebanon. a retrospective study of hospitalizations in a tertiary-care center
}

\begin{abstract}
Objective: A Brief Resolved Unexplained Event (BRUE) is a common condition in infancy. However, no epidemiological study has been undergone in Lebanon. This study aims to establish the prevalence and the characteristics of the population hospitalized after a BRUE.

Material and methods: A single-center retrospective study performed from 1998 to 2018 included 156 hospitalized infants, aged less than one year old, in a tertiary medical center. Data were collected from hospital archives.

Results: Most infants (92.9\%) hospitalized after a BRUE were aged less than 6 months old, with a slight masculine predominance $(52.6 \%)$. No pathognomonic symptom was identified. In terms of recurrence of the initial episode, it occurred in $55.1 \%$ of the cases. A transfer to a reanimation unit took place in $35.9 \%$ of patients, with an average stay of 6.3 days. Two infants were deceased and six were readmitted for the same chief complaint. Final confirmed diagnosis was a Gastro-Esophageal Reflux (GER) in $60.9 \%$. Consequently, a milk change occurred in $17.9 \%$ and a GER treatment in $65.4 \%$.
\end{abstract}

Conclusion: Infants younger than one year and hospitalized for a BRUE present a majority of confirmed GER diagnosis, and seem to have an excellent prognosis.

Keywords: brief resolved unexplained event (brue), infant, gastro-esophageal reflux (ger), epidemiology, reanimation
Volume 10 Issue 2 - 2020

\author{
Stephanie Antoun, Sandra Sabbagh \\ Department of Pediatrics, Hôtel-Dieu de France University \\ Medical Center, Lebanon
}

\begin{abstract}
Correspondence: Stephanie Antoun, Hôtel-Dieu de France University Medical Center, Saint Joseph University, Alfred Naccache Boulevard, Achrafieh, Beirut, BP I66830, Lebanon, Tel +96171004804, Email stephanieantoun@gmail.com
\end{abstract}

Received: April 03, 2020 | Published: April 17, 2020
Abbreviations: AAP, american academy of pediatrics; BRUE, brief resolved unexplained event; ALTE, apparent life threatening event; MENA, middle east and north africa; GER, gastro-esophageal reflux; CI, confidence interval; PICU, pediatric intensive care unit; RSV, respiratory syncytial virus; ECG, electrocardiogram; PSG, polysomnography; EEG, electroencephalogram; SUPC, sudden unexpected postnatal collapse; WGA, weeks of gestational age; NICU, neonatal intensive care unit

\section{Introduction}

The American Academy of Pediatrics (AAP) has implemented in 2016 new guidelines concerning Brief Resolved Unexpected Event (BRUE), hence replacing the previously used term of Apparent Life Threatening Event (ALTE). ${ }^{1-3}$ It is defined as a short, sudden and selfresolved episode, implicating one or more of what follows:
A. Cyanosis or pallor
B. Absent, decreased or irregular breathing
C. Change in tone
D. Altered levels of responsiveness

Infants are less than one year old, 2,4,5 and episodes last less than one minute, usually 20-30 seconds. ${ }^{6}$ This novel nomenclature restricted the previously heterogeneous clinical presentation. ${ }^{2-4}$ While precise prevalence of BRUE remains inconsistent throughout the different undergone studies, it varies around 0.58 to $2.46 \%$ in recent data. ${ }^{7,8}$ French and Italian recommendations find an age predilection of 2 to
6 months, with a mild masculine predominance and a recrudescence during autumn and winter. ${ }^{9-11}$ Many risk factors have been identified by Monti et al., ${ }^{12}$ though no direct correlation has been proven so far. ${ }^{12}$ However, finding the underlying cause remains controversial, with no cause identified in 15 to $65 \% 0^{1,10}$ Gastrointestinal pathologies are mostly incriminated, followed by infections, as well as neurologic, cardiologic, and metabolic disorders. ${ }^{8,13-16}$

Up until now, very few studies have described the epidemiologic characteristics in the Middle East and North Africa (MENA) countries. Five studies were conducted in Israel, by Ari, Tirosh, Weiss, Tirosh and Goldhammer concluding to excellent prognosis among BRUE and ALTE patients and a low-yield of performed tests, with a raised possibility of an abnormality in the autonomic function related to apnea and Gastro-Esophageal Reflux (GER)..$^{11,17-20}$ Similarly, two studies underwent in Iran by Aminiahidashti and Kadivar found, respectively, a predominance of gastric etiologies and an increased incidence of $11 \%$ with 18 patients admitted for ALTE. ${ }^{21,22}$ The goal of this study was to retrieve the epidemiologic characteristics of infants admitted for BRUE in Lebanon, as well as the final diagnosis and the therapeutic management.

\section{Materials and methods}

This is a retrospective observational single-centered study conducted in 2018 at Hôtel-Dieu de France, a tertiary-care center and university medical center affiliated to the Saint Joseph University and located in Beirut, Lebanon. Patients were identified by searching hospital discharge records for infants aged less than one year old with 
a chief complaint of a BRUE, over a period extending from January 1998 to June 2018. Included infants were those who complied to the AAP criteria for the definition of a BRUE (2). Infants with congenital or chronic conditions susceptible of causing syncopes were excluded. Other exclusion criteria were unlimited in duration or non-spontaneously resolved events. Ethical approval was obtained from Saint Joseph University's Medical Ethics Committee. Data obtained were anonymized before statistical analysis, and included demographic as well as medical details of the infant's hospitalization. Clinical characteristics were described by mean values, percentages and standard deviations. The Pearson Chi-two test and Fisher Exact test were used for categorical variables. Results are considered significant when $\mathrm{P}$ value is inferior to 0.05 , with a confidence interval (CI) of $95 \%$

\section{Results}

Final count of infants included in the study over the 20 -year period between 1998 and 2018 was 156, with $52.6 \%$ males and $47.4 \%$ females. Age distribution is shown in Table 1 and age categories were based on developmental stages according to the twentieth edition of Nelson's Textbook of Pediatrics. ${ }^{23}$ Mean age upon admission was 62.11 days (standard deviation 71.81), with a minimal age of 8 hours. Prevalence of admissions was variable over the years and is shown in Figure 1. Elements of past personal and family medical history are grouped in Table 1. Symptoms reported by parents were quite variable
(Figure 2). Hospitalization occurred within 24 hours of BRUE in $79.5 \%$ of cases $(n=124)$. In addition, a recurrence of the initial episode was found in $55.1 \%$ of cases $(n=86)$. The length of hospital stay varies between 1 and 25 days, with an average of 4.96 days (standard deviation 4.143). A transfer to the Pediatric Intensive Care Unit (PICU) was necessary in $35.9 \%(n=56)$ of the cases, with an average duration of 6.3 days (minimum 1 day; maximum 25 days; standard deviation 5.369). Specialist referrals were distributed among the various pediatric subspecialties, with a predominance for intensivists $(55.8 \%, \mathrm{n}=87)$, gastroenterology $(63.5 \%, \mathrm{n}=99)$, cardiology $(60.9 \%$, $\mathrm{n}=95)$ and neurology $(59.6 \%, \mathrm{n}=93)$.

Upon admission, initial clinical examination was unremarkable. Hospital stay was uncomplicated in $72.4 \%(n=113)$. Readmission occurred in $3.8 \%(\mathrm{n}=6)$ and two infants death were recorded during their stay $(1.3 \%)$. The final diagnosis retained corresponded in $60.9 \%$ to GER $(n=95)$; in $13.6 \%$ of cases $(n=21)$, no etiology was incriminated. The rest of the final diagnoses fall into several categories (Table 2). The cultures were positive in $16.7 \%$ of patients $(n=26)$, all locations combined. The germs most frequently found were the group of staphylococci $(5.6 \%$; $=9)$, as well as Escherichia coli $(2.5 \% ; n=4)$. The other germs were mainly bacteria: Pseudomonas aeruginosa $(1.9 \% ; \mathrm{n}=3)$, the streptococcus group $(1.9 \% \mathrm{n}=3)$, Enterobacter $(1.3 \% ; \mathrm{n}=2)$, Klebsiella pneumoniae $(1.3 \% \mathrm{n}=2)$. Respiratory Syncytial Virus was present in two occurrences (1.3\%), and Candida in only one $(0.6 \%)$.

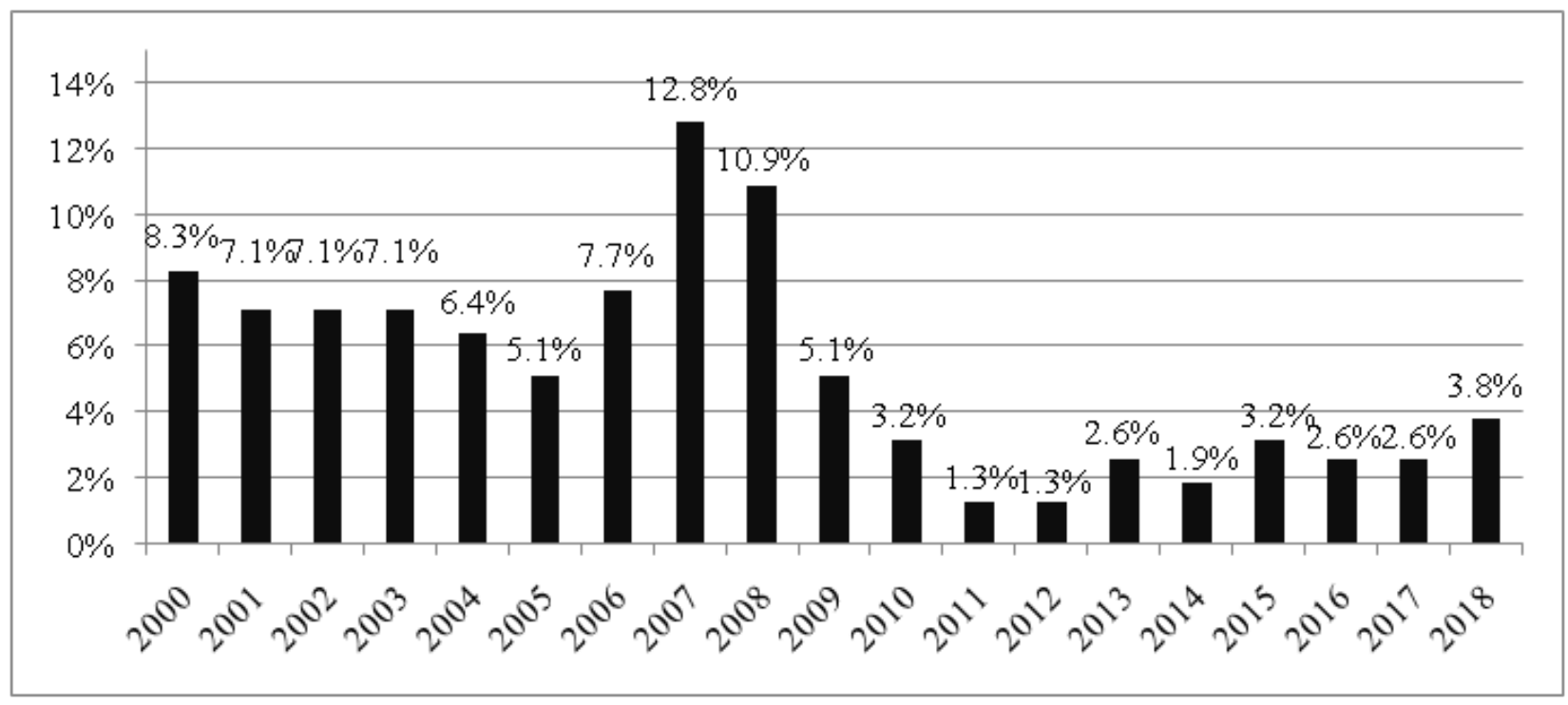

Figure I Prevalence of hospitalizations over the years.

Complementary tests carried out are distributed as follows: complete blood count in $94.9 \%(\mathrm{n}=148)$, hemostasis assessment in $17.3 \%(\mathrm{n}=27)$, blood electrolytes in $86.5 \%(\mathrm{n}=135)$, renal function in $40.4 \%(n=63)$, hepatic function in $26.9 \%(n=42)$, infectious assessment in $67.3 \%(\mathrm{n}=105)$, lumbar puncture in $30.8 \%(\mathrm{n}=48)$, chest radiography in $64.7 \%(\mathrm{n}=101)$, electrocardiogram (ECG) in $49.3 \%(\mathrm{n}=77)$, rhythmic Holter in $23.1 \%(\mathrm{n}=36)$, cardiac ultrasound in $33.3 \%(n=52)$, Upper Gastro-Intestinal Series in 32\% $(n=50)$, barium swallow in $5.1 \%(n=8)$, esophageal $\mathrm{pH}$ manometry in $44.9 \%(\mathrm{n}=70)$, polysomnography (PSG) in $9.6 \%(\mathrm{n}=15)$, digestive endoscopy in $11.5 \%(\mathrm{n}=18)$, brain imaging in $17.3 \%(\mathrm{n}=27)$, electroencephalogram $(\mathrm{EEG})$ in $50.6 \%(\mathrm{n}=79)$.
An abnormal test result that confirmed a diagnosis was found as follows: cardiac ultrasound in $0.9 \%(\mathrm{n}=17), \mathrm{ECG}$ in $3.2 \%(\mathrm{n}=5)$, Upper Gastro-Intestinal Series in $24.4 \%(\mathrm{n}=38)$, barium swallow in $2.6 \%(\mathrm{n}=4)$, esophageal $\mathrm{pH}$ manometry in $34 \%(\mathrm{n}=53), \mathrm{PSG}$ in $8.3 \%$ $(\mathrm{n}=13)$, EEG in $4.5 \%(\mathrm{n}=7)$.

During hospital stay, medications are often prescribed with antibiotics in $30.1 \%(\mathrm{n}=47)$, anti-epileptics in $11.5 \%(\mathrm{n}=18)$, caffeine in $1.9 \%(\mathrm{n}=3)$, and beta-blockers in $0.6 \%(\mathrm{n}=1)$. Monitoring of vital parameters is prescribed in $67.9 \%$ of cases $(n=106)$, as well as a headelevated position in $12.2 \%$ of cases $(n=19)$. At discharge, a change of milk occurred in $17.9 \%(\mathrm{n}=28)$ as follows: protein hydrolysates in 
$2.6 \%(\mathrm{n}=4)$, starch thickened milk in $8.3 \%(\mathrm{n}=13)$, carob thickened milk in $3.8 \%(\mathrm{n}=6)$, double thickened milk in $1.9 \%(\mathrm{n}=3)$, unspecified anti-reflux milk in $0.6 \%(\mathrm{n}=1)$, and hypoallergenic milk in $0.6 \%$ $(\mathrm{n}=1)$. Added to this, thickeners were also prescribed in $1.9 \%(\mathrm{n}=3)$, divided into Gelopectosis in $1.3 \%(n=2)$ and Biogaia in $0.6 \%(n=1)$. Anti-reflux drug treatment was started in $65.4 \%$ of infants $(n=102)$, with different molecules: Domperidone (28.2\%, $\mathrm{n}=44)$, Omeprazole $(19.2 \%, \mathrm{n}=30)$, Ranitidine $(19.9 \%, \mathrm{n}=31)$, Esomeprazole $(16 \%$, $\mathrm{n}=25)$, Metoclopramide $(14.7 \%, \mathrm{n}=23)$, Cisapride $(13.5 \%, \mathrm{n}=21)$. Bitherapy was enhanced in $41 \%$ of cases $(n=64)$ and tritherapy in $2.6 \%$ of cases $(n=4)$

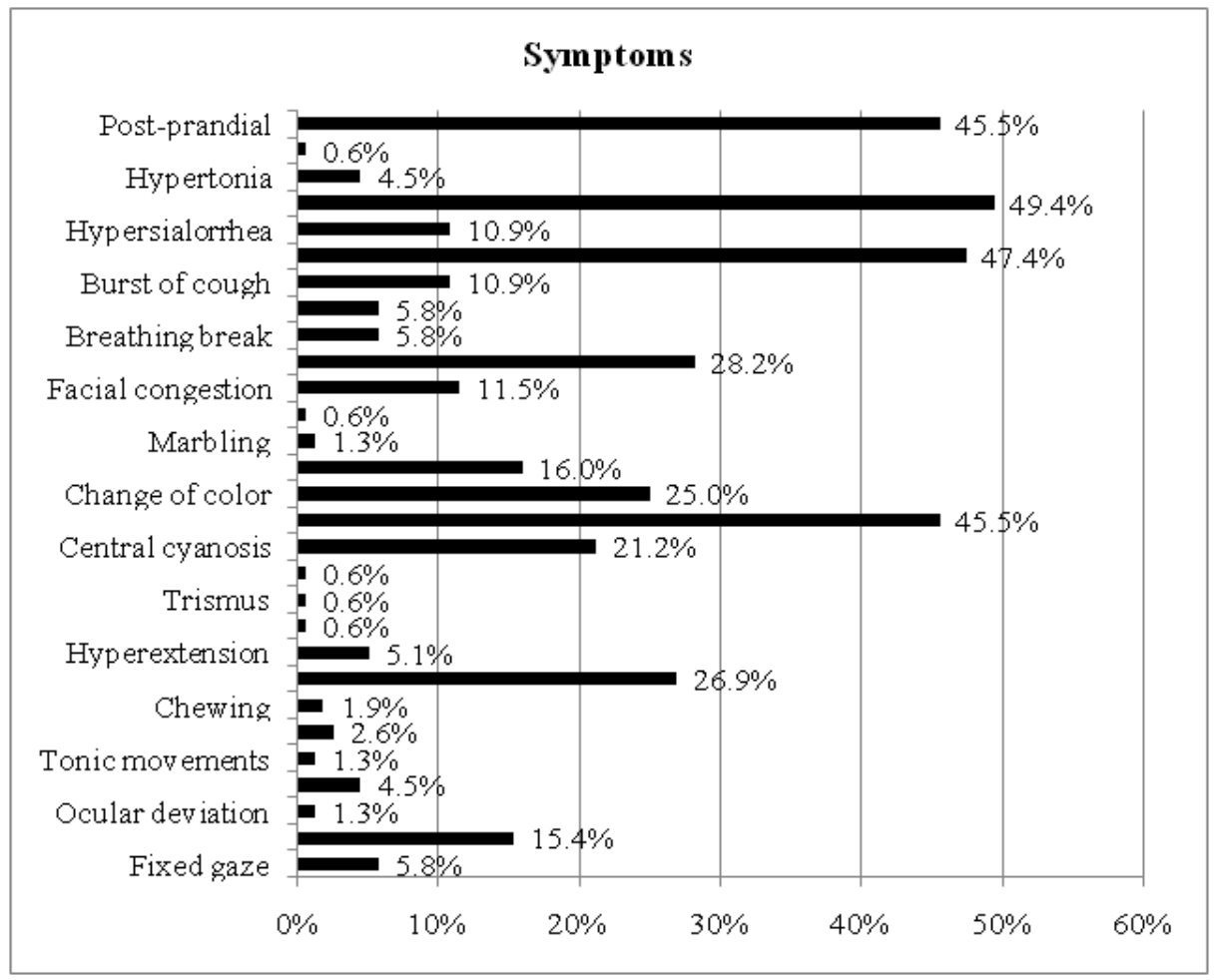

Figure 2 Symptoms described by parents.

Table I Past personal and family medical history

\begin{tabular}{lll}
\hline & & Prevalence (\%) \\
\hline Age on admission & $<24$ hours & $6.4 \%(n=10)$ \\
& $1-28$ days & $14.1 \%(n=22)$ \\
& $1-6$ months & $51.9 \%(n=81)$ \\
& $6-12$ months & $7.1 \%(n=11)$ \\
& $<28$ & $3.2(n=5)$ \\
Gestational age (WGA) & $28-32$ & $1.9(n=3)$ \\
Birth weight (g) & $32-37$ & $23.7(n=37)$ \\
& $>37$ & $71.2(n=111)$ \\
& $<1500$ & $5.1(n=8)$ \\
& $1500-2500$ & $19.2(n=30)$ \\
& $>2500$ & $46.2(n=7)$ \\
& Missing values & $29.5(n=46)$ \\
& $<18$ & 0 \\
Maternal age at birth (years) & $18-35$ & $25.6(n=40)$ \\
& $>35$ & $5.1(n=8)$ \\
& Missing values & $69.2(n=108)$ \\
& &
\end{tabular}




\begin{tabular}{|c|c|c|}
\hline & & Prevalence (\%) \\
\hline \multirow{3}{*}{ NICU stay } & Yes & $23.1(n=36)$ \\
\hline & No & $75.6(n=118)$ \\
\hline & Missing values & $1.3(n=2)$ \\
\hline \multirow{3}{*}{ Multiple pregnancy } & Yes & $12.2(=19)$ \\
\hline & No & $86.5(n=135)$ \\
\hline & Missing values & $1.3(n=2)$ \\
\hline \multirow{3}{*}{ Delivery mode } & Vaginal & $48.1(n=75)$ \\
\hline & C-section & $50.6(n=79)$ \\
\hline & Missing values & $1.3(n=2)$ \\
\hline \multirow{3}{*}{ Immunization } & Regular & $40.4(n=63)$ \\
\hline & Delayed & $53.8(n=84)$ \\
\hline & Missing values & $5.8(n=9)$ \\
\hline \multirow{2}{*}{ Prior episode of BRUE } & Yes & $6.4(n=10)$ \\
\hline & No & $93.6(n=146)$ \\
\hline \multirow{4}{*}{ Milk } & Exclusive Breastfeeding & $34(n=53)$ \\
\hline & Exclusive infant formula & $17.3(n=27)$ \\
\hline & Combined feeding & $46.2(n=72)$ \\
\hline & Missing values & $2.6(n=4)$ \\
\hline \multirow{6}{*}{ Anti-reflux milk } & Yes & $9(n=14)$ \\
\hline & No & $55.8(n=87)$ \\
\hline & Starch-thickened & $6.4(n=10)$ \\
\hline & Carob-thickened & $1.9(n=3)$ \\
\hline & Double thickened & $0.6(n=1)$ \\
\hline & Doesn't apply & $35.3(n=55)$ \\
\hline \multirow{2}{*}{ Milk thickening } & Yes & $2.6(n=4)$ \\
\hline & No & $97.4(n=153)$ \\
\hline \multirow{2}{*}{ Anti-reflux treatment } & Yes & $19.9(n=31)$ \\
\hline & No & $80.1(n=125)$ \\
\hline \multirow{2}{*}{ Family history of BRUE } & Yes & $0.6(n=1)$ \\
\hline & No & $99.3(n=146)$ \\
\hline
\end{tabular}

WGA, weeks of gestational age; NICU, neonatal intensive care Unit; BRUE, brief resolved unexplained event

Table 2 Final diagnosis and BRUE characteristics

\begin{tabular}{|c|c|c|c|c|c|c|c|}
\hline \multirow{2}{*}{ Final diagnosis } & \multirow{2}{*}{ Prevalence (\%) } & \multicolumn{2}{|c|}{ Symptoms onset (\%) } & \multicolumn{2}{|c|}{ Complications (\%) } & \multicolumn{2}{|c|}{ Surgical intervention (\%) } \\
\hline & & $<24 h$ & $>24 h$ & Yes & No & Yes & No \\
\hline GER & $60.9(n=95)$ & $46.8(n=73)$ & $14.1(n=22)$ & $16(n=25)$ & $44.9(n=70)$ & $5.1(n=8)$ & $55.8(n=87)$ \\
\hline $\begin{array}{l}\text { Hypertrophic pyloric } \\
\text { stenosis }\end{array}$ & $0.6(n=1)$ & 0 & $0.6(n=1)$ & 0 & $0.6(n=1)$ & $0.6(n=1)$ & 0 \\
\hline Cow's milk allergy & $1.3(n=2)$ & $1.3(n=2)$ & 0 & 0 & $1.3(n=2)$ & 0 & $1.3(n=2)$ \\
\hline Esophagitis & $1.9(n=3)$ & $0.6(n=1)$ & $1.3(n=2)$ & 0 & $1.9(n=3)$ & 0 & $1.9(n=3)$ \\
\hline Hiatal hernia & $0.6(n=1)$ & $0.6(n=1)$ & 0 & 0 & $0.6(n=1)$ & 0 & $0.6(n=1)$ \\
\hline Esophageal stenosis & $0.6(n=1)$ & $0.6(n=1)$ & 0 & $0.6(n=1)$ & 0 & $0.6(n=1)$ & 0 \\
\hline Erosive gastritis & $0.6(n=1)$ & $0.6(n=1)$ & 0 & 0 & $0.6(n=1)$ & 0 & $0.6(n=1)$ \\
\hline
\end{tabular}




\begin{tabular}{|c|c|c|c|c|c|c|c|}
\hline \multirow{2}{*}{ Final diagnosis } & \multirow{2}{*}{ Prevalence (\%) } & \multicolumn{2}{|c|}{ Symptoms onset (\%) } & \multicolumn{2}{|c|}{ Complications (\%) } & \multicolumn{2}{|c|}{ Surgical intervention (\%) } \\
\hline & & $<24 h$ & $>24 h$ & Yes & No & Yes & No \\
\hline Benign epilepsy & $3.2(n=5)$ & $3.2(n=5)$ & 0 & $1.3(n=2)$ & $1.9(n=3)$ & 0 & $3.2(n=5)$ \\
\hline Sandifer syndrome & I. $3(n=2)$ & $0.6(n=1)$ & $0.6(n=1)$ & 0 & I.3 $(n=2)$ & 0 & I. $3(n=2)$ \\
\hline Breath-holding spells & I.3 $(n=2)$ & $1.3(n=2)$ & 0 & $0.6(n=1)$ & $0.6(n=1)$ & 0 & $\mathrm{I} .3(\mathrm{n}=2)$ \\
\hline $\begin{array}{l}\text { Intracerebral } \\
\text { hemorrhage }\end{array}$ & $0.6(n=1)$ & $0.6(n=1)$ & 0 & 0 & $0.6(n=1)$ & 0 & $0.6(n=1)$ \\
\hline Meningeal hemorrhage & $0.6(n=1)$ & $0.6(n=1)$ & 0 & $0.6(n=1)$ & 0 & 0 & $0.6(n=1)$ \\
\hline Neonatal meningitis & $0.6(n=1)$ & $0.6(n=1)$ & 0 & $0.6(n=1)$ & 0 & 0 & $0.6(n=1)$ \\
\hline Sylvian artery ischemia & $0.6(n=1)$ & $0.6(n=1)$ & 0 & $0.6(n=1)$ & 0 & 0 & $0.6(n=1)$ \\
\hline Reflex syncope & $1.9(n=3)$ & I.3 $(n=2)$ & $0.6(n=1)$ & 0 & $1.9(n=3)$ & 0 & $1.9(n=3)$ \\
\hline Vagal hyperactivity & $0.6(n=1)$ & $0.6(n=1)$ & 0 & 0 & $0.6(n=1)$ & 0 & $0.6(n=1)$ \\
\hline Infectious risk & $1.9(n=3)$ & $1.9(n=3)$ & 0 & $0.6(n=1)$ & $1.3(n=2)$ & 0 & $1.9(n=3)$ \\
\hline Pertussis & $1.9(n=3)$ & I. $3(n=2)$ & $0.6(n=1)$ & $1.9(n=3)$ & 0 & 0 & $1.9(n=3)$ \\
\hline Sepsis & $0.6(n=1)$ & $0.6(n=1)$ & 0 & $0.6(n=I)$ & 0 & 0 & $0.6(n=I)$ \\
\hline RSV pulmonary infection & $0,6(n=1)$ & $0.6(n=1)$ & 0 & $0.6(n=1)$ & 0 & 0 & $0.6(n=1)$ \\
\hline RSV bronchiolitis & $1.9(n=3)$ & $1.9(n=3)$ & 0 & $0.6(n=1)$ & $1.3(n=2)$ & 0 & $1.9(n=3)$ \\
\hline Tachyaerophagia & $0.6(n=1)$ & 0 & $0.6(n=1)$ & 0 & $0.6(n=1)$ & 0 & $0.6(n=1)$ \\
\hline Non specified diagnosis & $13.5(n=21)$ & $12.2(n=19)$ & $1.3(n=2)$ & $1.3(n=2)$ & $12.2(n=19)$ & 0 & $13.5(n=21)$ \\
\hline
\end{tabular}

GER, gastro-esophageal reflux; RSV, respiratory syncytial virus

The results of Pearson test, giving an account of the relationship between the final diagnosis and the characteristics of the BRUE are shown in Table 2. The correlation with the onset of the BRUE finds a p-value of 0.287 ; for GER, p-value is 0.347 . The correlation with the presence of complications finds a p-value of 0.018; for GER, this value is 0.865 . The correlation with a surgical intervention finds a p-value of 0.135 ; for GER, this value is 0.072 . We note that out of the 5 Hemi-Nissen surgical procedures, a diagnosis of GER was confirmed; consequently, 5.3\% of GER required surgical treatment.

Furthermore, the relationship between BRUE recurrence and the duration separating the BRUE from hospital admission was evaluated by Fisher Exact Test, finding a recurrence in $36.5 \%(\mathrm{n}=57)$ when BRUE occurred within 24 hours before admission, and in $18.6 \%$ $(n=29)$ when it occurred previously, with a total of $55.1 \%(n=86)$ of recurrence. The p-value observed for this hypothesis comes back to 0.0001 .

\section{Discussion}

Previous studies on infant BRUE have highlighted the importance of clinical detection and diagnostic evaluation of this entity, most often benign, but which in some cases could include life-threatening pathologies. Concomitantly, there is currently no cohort nor an epidemiological assessment of this pathology in Lebanon. The population studied is one of the largest in Lebanon. In fact, not only does Hôtel-Dieu de France form one of the benchmark tertiary-care centers in Lebanese territory, but it is also one of the oldest University Medical Centers in the country, hence the number of patients gathered over the years. In addition, data collected over the twenty years all came from the same archiving system, including as well complementary test results. Age distribution of the population shows a clear predominance in the 1-6 months range; this is consistent with the data in the literature with a peak found between 3 and 4 months of life. ${ }^{9-11}$ However, only $6.4 \%$ of infants were admitted at less than 24 hours of life. Suggested in 2011 by the British Association of Perinatal Medicine (BAPM), the Sudden Unexpected Postnatal Collapse (SUPC) is a subcategory of the previously defined ALTE, specific to neonates. ${ }^{10}$ In our study, this low share of representativeness of SUPC could be due to the preponderance of exclusion criteria in a level III maternity, with an increased importance given to prenatal diagnoses, in particular congenital heart diseases. ${ }^{24}$ Furthermore, with a sex ratio of 1.1:1, our results concur with the slight male predominance mentioned in previous studies. ${ }^{9}$

However, the prevalence of admissions was quite variable over the years (Figure 1), with a cumulative percentage of $72.4 \%$ of total admissions before the year 2009. Subsequently, the number of hospitalized cases was in a constant decrease, to no longer exceed 6 admissions per year. This could be due to several factors. On one hand, with the national decentralization policy, University Medical Centers are multiplying on the Lebanese territory and multidisciplinary teams are gaining expertise; henceforth, it is no longer necessary to refer to a single center. On the other hand, improved prenatal screening allowed better management of the underlying vulnerability factors, thereby reducing the occurrence of BRUEs.

In our study, pregnancy and past medical history characteristics were unremarkable (Table 1). In addition, the variability of symptoms described by the parents (Figure 2) corresponds to the clinical heterogeneity described in the literature..$^{2-4}$ However, some remain preponderant, namely hypotonia (49.4\%), peripheral cyanosis $(45.5 \%)$ and regurgitation (47.4\%). Apnea (28.2\%) and loss of contact (26.9\%) 
were less common. With an added normal initial physical examination found in most admissions, criteria defined by the AAP in 2016 were met. ${ }^{1,2,6}$ Although a briefness of the episode was found in $17.3 \%$ of cases, Hauk specified that BRUEs last less than 20 to 30 seconds. $^{6}$ In our study, hospital stay lasted an average of 4.96 days [ \pm 4.413$]$, with a transfer to PICU in $35.9 \%$ of the cases and a stay duration of 6.3 days $[ \pm 5.369]$ in the latter. Our results remain consistent with previous data, the average of which varied between 4.4 and 10 days. ${ }^{16}$

Given that the population was recruited from a tertiary-care center, access to specialist consultations was easily granted, and occurred in 55 to $63 \%$. Opposed to this, previous recommendations have mentioned resorting to specialists only in severe hospitalized cases. ${ }^{10}$ The fact remains that the specialties most requested in this context remain cardiology, gastroenterology and neurology; ${ }^{10,25}$ this was noted by our study as well. Moreover, an intensivist consultation was undertaken in $55.8 \%$, while there was no request for a metabolician's opinion, unlike recommended by Italian guidelines. ${ }^{10}$ Due to the divergence of recommendations for first-line complementary explorations $, 1,25$ those undertaken in our center fall within a fairly broad spectrum, with however a predominance for complete blood count $(94.9 \%)$ and blood electrolytes (86.5\%). Infectious assessment (67.3\%), chest radiography (64.7\%), EEG (50.6\%), esophageal $\mathrm{pH}$ monitoring $(44.9 \%)$ and ECG $(49.3 \%)$ follow. In other words, in more than half of the cases, complementary tests included an infectious assessment, as was as gastroenterological, respiratory, cardiological and neurological. Consequently, this approach took place in accordance with the majority of recommendations, hence corresponding to the etiologies most frequently incriminated in BRUEs. ${ }^{26-29}$ Furthermore, Piumelli et al., ${ }^{10}$ found similar data for cardiological and neurological examinations. In their study, infants underwent a cardiac ultrasound in $50 \%$, an ECG in 50\% and an EEG in 60\%. Henceforth, the importance attached to cardiac and neurological examinations could reflect clinicians' concern regarding the patients' vital prognosis. ${ }^{10}$

However, the etiological value of a complementary test was variable, with higher prevalence for digestive explorations (Upper Gastro-Intestinal Series 24.4\%; esophageal pH monitoring 34\%), and lower for cardiac explorations (cardiac ultrasound 0.9\%; ECG 3, 2\%) or neurological (EEG 4.5\%). This contrasts with the results reported by Brand et al, finding a prevalence of $5.9 \%(30)$. As for the infectious agents found, our results remain less conclusive than those objectified in the literature, insofar as staphylococci were predominant (5.6\%); this bacteria, being commensal of the human skin, cannot be at the origin of a causal link inducing BRUEs. ${ }^{10,31-33}$

Our study found a large etiological predominance attributed to confirmed GER $(60.9 \%)$, all complementary tests combined. In spite of the lack of an exact prevalence for the implication of GER in BRUEs, particularly due to the bias caused by intercurrent apnea, previous studies converge to attribute a significant part for gastroenterological pathologies in triggering BRUEs, ranging from 20 to $54 \%{ }^{10,34-40}$ However, in $13.6 \%$ of admissions, and despite all workup, no etiology was incriminated in BRUEs; this contrasts with the figures, although variable, found in previous studies, ranging from 15 to $65 \%{ }^{1,10}$ Admittedly, it is customary to correlate a BRUE that occurred post-meal to a causal GER. ${ }^{25}$ Our results show a postprandial occurrence in $45.5 \%$ of the cases and an association with regurgitation in $47.4 \%$, thus ensuring that the rest of the GER identified do not exhibit these signs, therefore becoming non-pathognomonic. This is in line with the recommendations of the North American Society for Pediatric Gastroenterology, Hepatology and Nutrition (NASPGHAN) and the European Society for Pediatric Gastroenterology, Hepatology and Nutrition (ESPGHAN) that do not endorse specific therapeutic management in the event of a combination of a BRUE with regurgitation..$^{41,42}$

Regarding the onset of BRUEs, there is no statistically significant correlation between the delay separating the latter and hospital admission, and the final diagnosis retained (p-value: 0.287) (Table 2); this hypothesis has not been evoked previously. On the other hand, recurrence of the episodes was found in $55.1 \%$ of the cases, similar to previous data, which describes a range between 30 and $60 \%{ }^{10,43-45}$ Nonetheless, when hospitalization occurs more than 24 hours after the onset of a BRUE, reiteration of the episode takes place in $18.6 \%$ of cases, with a high statistical significance in our study (p-value: $0.0001)$. Even if the majority of studies agree on a reduction in the risk of a new occurrence with time, ${ }^{43-45}$ our results go against them, and confirm in this way the necessity of cardiorespiratory monitoring. ${ }^{10}$

The other complications listed, however, remain inconclusive. In particular, mortality rate was $1.3 \%$ following an admission for BRUE, slightly exceeding that previously described. ${ }^{46-48}$ The fact remains that the correlation between the occurrence of a complication and the final diagnosis remains significant (p-value: 0.018). On the one hand, this is linked to the clinical and etiological heterogeneity of BRUEs. ${ }^{2-4}$ However, on the other hand, Piumelli had also shown that complications could increase with the length of hospital stay. ${ }^{10}$ Their results were similar to those found by Gatto et al in a 4-year retrospective study conducted in 2018. ${ }^{5}$ Several anti-reflux molecules were suggested and prescribed, namely proton pump inhibitors (Esomeprazole, Omeprazole), dopamine receptor antagonists (Domperidone, Metoclopramide), serotonin receptor agonists (Cisapride) and antihistamines (Ranitidine). However, we find a relative tendency to single out Domperidone; this goes against what has been described in the literature, in particular by Duncan, favoring the use of acid suppressants. ${ }^{48}$ Nevertheless, milk changing or thickening was prescribed in $17.9 \%$ of cases, all forms combined. The meta-analysis undertaken by the National Institute for Health and Care Excellence (NICE) in 2015 confirms a reduction in regurgitation and exposure to reflux acidity; however, there is no established causal relationship with the impact on BRUEs, and therefore no recommendations have been issued on this subject. ${ }^{49}$ Although carried out on a large and fairly representative sample of the Lebanese population, the results of our study could not be extrapolated nationwide. In fact, over the years, the development of tertiary-care centers at the national level favors the distribution of specialized medicine and consequently reduces the number of cases referred from peripheral regions. In spite of this, there are no currently published studies concerning the epidemiology of BRUEs in Lebanon; this may be the subject of further multicenter study. Another limitation to our study could also be due to its retrospective nature, making it difficult to collect certain data, in particular concerning semiology and physical examination. Cohort follow-up would be interesting, especially for the evaluation of the long-term consequences of hospitalized patients.

\section{Conclusion}

BRUE is considered, par excellence, an entity with clinical and etiological heterogeneity, without a well-defined etiopathogenesis. However, there is no consensus in the literature concerning the prevalence of this pathology, nor its characteristics and adequate management. This study, identifying patients hospitalized for BRUE from January 2008 to June 2018, confirmed the preponderance of 
GER as the main underlying etiology, a statement comparable to the data in the literature. It remains the only cohort described in Lebanon and MENA region over a period of twenty years. However, the results obtained remain only descriptive, hampered by the retrospective nature of the study, in the absence of a comparative control group. An assessment of the long-term consequences, as well as the predisposing factors, could be the subject of a later study, in order to develop good practice recommendations adapted to the local population.

\section{Acknowledgments}

None.

\section{Conflicts of interest}

The authors declare there are no conflicts of interest.

\section{Funding}

None.

\section{References}

1. Colombo M, Katz ES, Bosco A, et al. Brief resolved unexplained events Retrospective validation of diagnostic criteria and risk stratification. Pediatr Pulmonol. 2019;54(1):61-65.

2. Tieder JS, Bonkowsky JL, Etzel RA, et al. Brief Resolved Unexplained Events (Formerly Apparent Life-Threatening Events) and Evaluation of Lower-Risk Infants: Executive Summary. Pediatrics. 2016;137(5).

3. National Institutes of Health Consensus Development Conference on Infantile Apnea and Home Monitoring, Sept 29 to Oct 1, 1986. Pediatrics. 1987;79(2):292-299.

4. Arane K, Claudius I, Goldman RD. Brief resolved unexplained event Can Fam Physician. 2017;63(1):39-41.

5. Gatto A, Paglietti MG, Bocchi MB, et al. Brief resolved unexplained events and apparent life-threatening events: the wall between guidelines and clinical practice. Acta Paediatr. 2019.

6. Hauk L. AAP Releases Guideline on Brief Resolved Unexplained Events (BRUEs) and Evaluation of Lower-Risk Infants. Am Fam Physician. 2017;95(5):330-301.

7. Kiechl-Kohlendorfer U, Hof D, Peglow UP, et al. Epidemiology of apparent life threatening events. Arch Dis Child. 2005 ;90(3):297-300.

8. Semmekrot BA, Van Sleuwen BE, Engelberts AC, et al. Surveillance study of apparent life-threatening events (ALTE) in the Netherlands. Eur J Pediatr. 2010;169(2):229.

9. Foucaud P, Hau I, Briand-Huchet E, et al. Malaise du nourrisson: Recommandations du Groupe de Pédiatrie Générale. Paris: Groupe de Pédiatrie Générale. 2013.

10. Piumelli R, Davanzo R, Nassi N, et al. Apparent Life-Threatening Events (ALTE): Italian guidelines. Ital J Pediatr. 2017;43(1):111

11. Ari A, Atias Y, Amir J. Long-Term Follow-Up of Infants After a Brief Resolved Unexplained Event-Related Hospitalization. Pediatr Emerg Care. 2019

12. Monti MC, Borrelli P, Nosetti L, et al. Incidence of apparent lifethreatening events and post-neonatal risk factors. Acta Paediatr. 2017;106(2):204-210.

13. Kahn A. Recommended clinical evaluation of infants with an apparent life-threatening event. Consensus document of the European Society for the Study and Prevention of Infant Death, 2003. Eur J Pediatr. 2004;163(2):108-115.
14. McGovern MC, Smith MBH. Causes of apparent life threatening events in infants: a systematic review. Arch Dis Child. 2004;89(11):1043-1048.

15. Wijers MMJW, Semmekrot BA, de Beer HJA, et al. Multidisciplinary guidelines for "Apparent life threatening event" (ALTE). Ned Tijdschr Geneeskd. 2009;153:A590.

16. Tieder JS, Cowan CA, Garrison MM, et al. Variation in Inpatient Resource Utilization and Management of Apparent Life-Threatening Events. J Pediatr. 2008;152(5):629-635.

17. Tirosh E, Ariov-Antebi N, Cohen A. Autonomic function, gastroesophageal reflux in apparent life threatening event. Clin Auton Res Off J Clin Auton Res Soc. 2010;20(3):161-166.

18. Weiss K, Fattal-Valevski A, Reif S. How to evaluate the child presenting with an apparent life-threatening event? Isr Med Assoc J IMAJ. 2010;12(3):154-157.

19. Tirosh E, Avengulov I, Jaffe M. Idiopathic apparent life-threatening event in Northern Israel. J Paediatr Child Health. 2006;42(1-2):33-36.

20. Goldhammer EI, Zaid G, Tal V, et al. QT dispersion in infants with apparent life-threatening events syndrome. Pediatr Cardiol. 2002;23(6):605-607.

21. Kadivar M, Yaghmaie B, Allahverdi B, et al. Apparent life-threatening events in neonatal period: clinical manifestations and diagnostic challenges in a pediatric referral center. Iran J Pediatr. 2013;23(4):458466.

22. Aminiahidashti H. Infantile Apparent Life-Threatening Events, an Educational Review. Emerg Tehran Iran. 2015;3(1):8-15.

23. Kliegman R, Stanton B, St Geme J, et al. Nelson Textbook of Pediatrics 20th, illustrated ed. Elsevier Health Sciences; 2015. p. 5111.

24. Chehab G, Chedid P, Saliba Z, et al. Congenital cardiac disease and inbreeding: specific defects escape higher risk due to parental consanguinity. Cardiol Young. 2007;17(4):414-422.

25. Zambelli L, Battisti O. How I explore an Apparent Life Threatening Event of the Infant. Rev Med Liege. 2016;71(4):198-203.

26. Davies F, Gupta R. Apparent life threatening events in infants presenting to an emergency department. Emerg Med J EMJ. 2002;19(1):11-16.

27. Altman RL, Li KI, Brand DA. Infections and apparent life-threatening events. Clin Pediatr (Phila). 2008;47(4):372-378.

28. Duncan DR, Amirault J, Mitchell P, et al. Oropharyngeal dysphagia is strongly correlated with apparent life-threatening events. J Pediatr Gastroenterol Nutr. 2017;65(2):168

29. Macchini F, Morandi A, Cognizzoli P, et al. Acid Gastroesophageal Reflux Disease and Apparent Life-Threatening Events: Simultaneous pH-metry and Cardiorespiratory Monitoring. Pediatr Neonatol. 2017;58(1):43-47.

30. Brand DA, Altman RL, Purtill K, et al. Yield of diagnostic testing in infants who have had an apparent life-threatening event. Pediatrics. 2005;115(4):885-893.

31. Baker KA, Ryan ME. RSV infection in infants and young children What's new in diagnosis, treatment, and prevention? Postgrad Med 1999;106(7):97-111.

32. Crowcroft NS, Booy R, Harrison T, et al. Severe and unrecognised: pertussis in UK infants. Arch Dis Child. 2003;88(9):802-806.

33. Al Khushi N, Côté A. Apparent life-threatening events: Assessment, Risks, Reality. Paediatr Respir Rev. 2011;12(2):124-132.

34. Arad-Cohen N, Cohen A, Tirosh E. The relationship between gastroesophageal reflux and apnea in infants. JPediatr. 2000;137(3):321326. 
35. Ing AJ, Ngu MC, Breslin AB. Obstructive sleep apnea and gastroesophageal reflux. Am J Med. 2000;108(4):120-125.

36. Amin RS. Gastroesophageal reflux and infant apnea. J Pediatr. 2000;137(3):298-300.

37. Mousa H, Woodley FW, Metheney M, et al. Testing the association between gastroesophageal reflux and apnea in infants. J Pediatr Gastroenterol Nutr. 2005;41(2):169-177.

38. Wenzl TG, Schenke S, Peschgens T, et al. Association of apnea and nonacid gastroesophageal reflux in infants: investigations with the intraluminal impedance technique. Pediatr Pulmonol. 2001;31(2):144 149.

39. Corvaglia L, Zama D, Spizzichino M, et al. The frequency of apneas in very preterm infants is increased after non $\square$ acid gastro $\square$ esophageal reflux. Neurogastroenterol Motil. 2011;23(4):303-e152.

40. Doshi A, Bernard-Stover L, Kuelbs C, et al. Apparent life-threatening event admissions and gastroesophageal reflux disease: the value of hospitalization. Pediatr Emerg Care. 2012;28(1):17-21.

41. Smits MJ, van Wijk MP, Langendam MW, et al. Association between gastroesophageal reflux and pathologic apneas in infants: a systematic review. Neurogastroenterol Motil. 2014;26(11):1527-1538.

42. Rosen R, Vandenplas Y, Singendonk M, et al. Pediatric gastroesophageal reflux clinical practice guidelines: joint recommendations of the North American Society for Pediatric Gastroenterology, Hepatology, and Nutrition and the European Society for Pediatric Gastroenterology, Hepatology, and Nutrition. $J$ Pediatr Gastroenterol Nutr. 2018;66(3):516-554.
43. Côté A, Hum C, Brouillette RT, et al. Frequency and timing of recurrent events in infants using home cardiorespiratory monitors. J Pediatr. 1998;132(5):783-789.

44. Côté A. Home and hospital monitoring for ALTE. Paediatr Respir Rev. 2006;7:S199-201.

45. Dewolfe CC. Apparent life-threatening event: a review. Pediatr Clin North Am. 2005;52(4):1127-1146.

46. Kant S, Fisher JD, Nelson DG, et al. Mortality after discharge in clinically stable infants admitted with a first-time apparent life-threatening event. Am J Emerg Med. 2013;31(4):730-733.

47. Waite AJ, Coombs RC, McKenzie A, et al. Mortality of babies enrolled in a community-based support programme: CONI PLUS (Care of Nex Infant Plus). Arch Dis Child. 2015;100(7):637-642.

48. Duncan DR, Growdon AS, Liu E, et al. The Impact of the American Academy of Pediatrics Brief Resolved Unexplained Event Guidelines on Gastrointestinal Testing and Prescribing Practices. J Pediatr. $2019 ; 211: 112-119$

49. Davies I, Burman-Roy S, Murphy MS. Gastro-oesophageal reflux disease in children: NICE guidance. BMJ. 2015;350:g7703 